LIVER

\title{
Increased anandamide induced relaxation in mesenteric arteries of cirrhotic rats: role of cannabinoid and vanilloid receptors
}

\author{
M Domenicali, J Ros, G Fernández-Varo, P Cejudo-Martín, M Crespo, M Morales-Ruiz, \\ A M Briones, J-M Campistol, V Arroyo, E Vila, J Rodés, W Jiménez
}

Gut 2005;54:522-527. doi: 10.1136/gut.2004.051599

See end of article for authors' affiliations

Correspondence to: Dr W Jiménez,

Laboratorio Hormonal, Hospital Clinic Universitari, Villarroel 170, Barcelona 08036, Spain; wjimenez@ clinic.ub.es

Revised version received 7 October 2004

Accepted for publication 8 October 2004
Background and aims: Anandamide is an endocannabinoid that evokes hypotension by interaction with peripheral cannabinoid $\mathrm{CB} 1$ receptors and with the perivascular transient receptor potential vanilloid type 1 protein (TRPV1). As anandamide has been implicated in the vasodilated state in advanced cirrhosis, the study investigated whether the mesenteric bed from cirrhotic rats has an altered and selective vasodilator response to anandamide.

Methods: We assessed vascular sensitivity to anandamide, mRNA and protein expression of cannabinoid CBI receptor and TRPV1 receptor, and the topographical distribution of cannabinoid $C B 1$ receptors in resistance mesenteric arteries of cirrhotic and control rats.

Results: Mesenteric vessels of cirrhotic animals displayed greater sensitivity to anandamide than control vessels. This vasodilator response was reverted by CB1 or TRPV1 receptor blockade, but not after endothelium denudation or nitric oxide inhibition. Anandamide had no effect on distal femoral arteries. CB1 and TRPV1 receptor protein was higher in cirrhotic than in control vessels. Neither CB1 mRNA nor protein was detected in femoral arteries. Immunochemistry showed that $C B 1$ receptors were mainly in the adventitia and in the endothelial monolayer, with higher expression observed in vessels of cirrhotic rats than in controls.

Conclusions: These results indicate that anandamide is a selective splanchnic vasodilator in cirrhosis which predominantly acts via interaction with two different types of receptors, CBI and TRPV1 receptors, which are mainly located in perivascular sensory nerve terminals of the mesenteric resistance arteries of these animals.
$\mathrm{T}$ he endogenous cannabinoid family includes anandamide (AEA), 2-arachydonyl glycerol, virodhamine, noladinether, and $\mathrm{N}$-arachidonoyl-dopamine. ${ }^{1}$ These substances elicit cardiovascular effects, such as hypotension, via activation of the cannabinoid CBl receptor. ${ }^{2}$ AEA also promotes vasodilation in some areas, such as the splanchnic vascular bed. ${ }^{3}$ The $\mathrm{CB} 1$ receptor is peripherally located in endothelial and smooth muscle cells and in perivascular nerves. ${ }^{24}$ Moreover, AEA can also interact with the transient receptor potential vanilloid type l protein (TRPVl), which is also known as VRl receptor and belongs to the large family of TRP ion channels and is expressed in perivascular nerves. ${ }^{4}$

Recent studies have identified the endogenous cannabinoid system as a mediator involved in the pathogenesis of arterial hypotension in cirrhosis. ${ }^{56}$ However, whereas the ability to produce increased amounts of endocannabinoids is clearly established in experimental and human cirrhosis, no study has assessed either vascular reactivity to AEA in cirrhotic resistance vessels or whether this response is differentially regulated depending on the vascular territory. Therefore, the aim of the current investigation was to assess whether mesenteric resistance arteries of cirrhotic rats with ascites display an altered and differential response to AEA. Our results demonstrated that this endocannabinoid produced a markedly enhanced vasorelaxant effect in mesenteric arteries of cirrhotic rats with ascites, a phenomenon not observed in the peripheral vasculature, mediated by both CBI and TRPVI receptors located mainly in perivascular nerves. These findings point to the endocannabinoid system as an important pathogenic mediator of splanchnic arteriolar vasodilation in advanced liver disease.

\section{MATERIAL AND METHODS}

The study was performed in cirrhotic adult male Wistar rats with ascites and in control Wistar rats (Charles-River, Saint Aubin les Elseuf, France). Cirrhosis was induced with $\mathrm{CCl}_{4}$ following a method described previously. ${ }^{7}$

Isolation of femoral and mesenteric arteries was performed as described by Wigg and colleagues. ${ }^{8}$ Briefly, rats aged 2428 weeks were killed by decapitation and the mesenteric bed and femoral arteries were removed and placed in Krebs solution (mM): $120.0 \mathrm{NaCl}, 5.0 \mathrm{KCl}, 25.0 \mathrm{NaHCO}_{3}, 11.0$ glucose, $1.0 \mathrm{KH}_{2} \mathrm{PO}_{4}, 1.2 \mathrm{MgSO}_{4}$, and $2.5 \mathrm{CaCl}_{2}$, equilibrated with $5 \% \quad \mathrm{CO}_{2}-95 \% \quad \mathrm{O}_{2}$. To asses vascular reactivity in resistance vessels, distal branches of the femoral artery and tertiary branches of the mesenteric arcades (both 200$300 \mu \mathrm{m}$ external diameter) were dissected and segments ( $2 \mathrm{~mm}$ ) were individually mounted on a small vessel wire myograph (Model 610M; JP Trading, Aarhus, Denmark). The integrity of the vessel was assessed on examination of the maximal force developed to $10 \mu \mathrm{M}$ of the $\alpha_{1}$ adrenoreceptor selective agonist phenylephrine and by subsequent determination of the effect of the endothelium dependent vasodilator acetylcholine (ACh $10 \mu \mathrm{M})$; relaxation $\geqslant 80 \%$ was taken as indicating endothelium intact vessels. The preparations were allowed to recover for 30 minutes and were then primed

Abbreviations: TRPV1, transient receptor potential vanilloid type 1 protein; $\mathrm{AEA}$, anandamide; $\mathrm{ACh}$, acetylcholine; RT, reverse transcribed; $\mathrm{PCR}$, polymerase chain reaction; L-NAME, N $\omega$-nitro-L-arginine-methylester; NO, nitric oxide; CGRP, calcitonin gene related peptide; CB receptor, cannabinoid receptor; pA2, apparent affinity dissociation constant; $V_{\text {max }}$, maximum response; SDS, sodium dodecyl sulphate 
three times over 30 minutes with phenylephrine (10 $\mu \mathrm{M})$. Vessels were rinsed and thereafter Krebs solution contained indomethacin $(1 \mu \mathrm{M})$ to prevent the influence of cyclooxygenase derived products throughout the subsequent experiments. Concentration-response curves to AEA were performed in mesenteric resistance arteries from cirrhotic and control rats precontracted with $10 \mu \mathrm{M}$ phenylephrine. In preliminary experiments we found that $10 \mu \mathrm{M}$ phenylephrine produced a similar constrictor response in mesenteric vessels of cirrhotic (9.68 (1.55) mN; $\mathrm{n}=7)$ and control (9.81 (1.49) $\mathrm{mN} ; \mathrm{n}=6$ ) rats.

When indicated, endothelium denuded vessels were obtained by gently rubbing the intimal surface with a human hair. Vessels were considered endothelium denuded when ACh induced relaxation was less than $10 \%$ of precontracted tone.

Phenylephrine $(10 \mu \mathrm{M})$ precontracted resistance arteries isolated from cirrhotic and control rats were exposed to cumulative concentrations of AEA, ranging from $10^{-8}$ to $5 \times 10^{-4} \mathrm{M}$, in a wire myograph with four parallel independent chambers to evaluate the vessel response from the same rat under different experimental conditions. Firstly, the vasorelaxant effect of AEA was assessed. Next, concentrationresponse curves to AEA were performed in endothelium denuded arteries or in intact arteries in the absence or presence of the nitric oxide synthase inhibitor N $\omega$-nitro-Larginine-methyl-ester (L-NAME $100 \mu \mathrm{M}$ ) and the neurotoxin capsaicin (10 $\mu \mathrm{M}$ for one hour), respectively. The vasorelaxant effect of AEA under conditions of CBI receptor blockade with SR141716A $(3 \mu \mathrm{M})$ or TRPVI receptor blockade with capsazepine $(5 \mu \mathrm{M})$, alone or in combination, was evaluated. Finally, femoral resistance arteries isolated from cirrhotic and control rats were exposed to cumulative doses of AEA, as described above.

\section{CB 1 and TRPV 1 mRNA expression in mesenteric and femoral arteries of control and cirrhotic rats}

Total RNA was extracted from second and third order mesenteric arteries and distal femoral arteries from control and cirrhotic rats, and brain from control rats using a commercially available kit (Trizol Reagent; Life Technologies, Gaithersburg, Maryland, USA). Total RNA (0.5 $\mu \mathrm{g})$ was reverse transcribed (RT) using a complementary DNA synthesis kit (Promega, Madison, Wisconsin, USA). Primers for CBl receptor (sense: 5' -TGT GGG CAG CCT GTT CCT CA3'; antisense: 5'-GGG TTT TGG CCA GCC TAA TGT C-3') and for TRPVI (sense: 5'-GGA CGT TGC CCG GAA GAC AGA C3'; antisense: 5'-CTT CAG CGT GGG GTG GAG TTT G-3') were prepared according to the rat $\mathrm{CBl}$ mRNA sequence (GenBank accession No NM_012784) and the rat TRPVl gene sequence (GenBank accession No AF327067), respectively. Polymerase chain reaction (PCR) for CBl and TRPVl were performed using a DNA amplification kit (Life Technologies). PCR products were sequenced to check correct amplification.

\section{CB 1 and TRPV 1 protein expression in mesenteric and femoral arteries of control and cirrhotic rats}

Distal branches of the femoral artery and tertiary branches of the mesenteric artery from control and cirrhotic rats were homogenised in a Tris $\mathrm{HCl} 20 \mathrm{mM}$ pH 7.4 buffer, containing $1 \%$ Triton $\mathrm{X}-100,0.1 \%$ sodium dodecyl sulphate (SDS), $50 \mathrm{mM} \mathrm{NaCl}, 2.5 \mathrm{mM}$ EDTA, $1 \mathrm{mM} \mathrm{Na} \mathrm{P}_{2} \mathrm{O}_{7} \cdot 10 \mathrm{H}_{2} \mathrm{O}, 20 \mathrm{mM}$ $\mathrm{NaF}, 1 \mathrm{mM} \mathrm{Na} \mathrm{VO}_{4}, 2 \mathrm{mM}$ Pefabloc, and a cocktail of protease inhibitors (Complete Mini; Roche, Basel, Switzerland). To detect the $\mathrm{CBl}$ receptor, $80 \mu \mathrm{g}$ of the denatured proteins were run on a $7.5 \%$ SDS-polyacrylamide gel and transferred to nitrocellulose membranes which were blocked with 5\% powdered defatted milk in TTBS buffer (50 mM Tris- $\mathrm{HCl}, \mathrm{pH} 8$, containing $0.05 \%$ Tween 20 and
$150 \mathrm{mM} \mathrm{NaCl}$ ) overnight at $4^{\circ} \mathrm{C}$, and were then incubated with a primary rabbit polyclonal antibody against the CBI receptor (1:750; Cayman Chemical, Ann Arbor, Michigan, USA), followed by incubation with horseradish peroxidase conjugated rabbit antibody (1:5000; Amersham, Little Chalfont, Buckinghamshire, UK). The denatured proteins $(80 \mu \mathrm{g})$ were run on a $10 \%$ SDS-polyacrylamide gel and transferred to nitrocellulose membranes, blocked with $2 \%$ bovine serum albumin in TTBS buffer $(50 \mathrm{mM}$ Tris- $\mathrm{HCl}$, pH 8, containing $0.05 \%$ Tween 20 and $150 \mathrm{mM} \mathrm{NaCl}$ ), and then incubated with a primary rabbit polyclonal antibody against the capsaicin receptor (1:750, TRPVl; Chemicon, Temecula, California, USA), followed by incubation with horseradish peroxidase conjugated rabbit antibody (1:2000; Amersham). Bands were visualised by chemiluminescence (ECL western blotting analysis system; Amersham). Relative expression of $\mathrm{CBl}$ and vanilloid receptors was determined by densitometric scanning (Phoretix International Ltd, Newcastle, UK).

\section{Immunohistochemical localisation of CB 1 receptor}

Third order branches of the mesenteric artery from control and cirrhotic rats were fixed with $4 \%$ phosphate buffered paraformaldehyde (one hour) and included in OCT. Cross sections $(14 \mu \mathrm{m})$ were cut onto gelatin coated slides. Sections were incubated with a primary rabbit polyclonal antibody against the CBl receptor (1:50; Cayman Chemical) in phosphate buffered saline containing $2 \%$ bovine serum albumin for one hour at $37^{\circ} \mathrm{C}$. After washing, rings were incubated with the secondary antibody, a donkey antirabbit IgG conjugated to Cy3 (1:200; Jackson Immuno Research Laboratories, West Grove, Pennsylvania, USA), for a further one hour at $37^{\circ} \mathrm{C}$. Immunofluorescent signals were viewed with a confocal microscope (Leica TCS SP2) with a $\times 40_{\text {oil }}$ objective. Whole mesenteric resistance arteries from cirrhotic and control rats were processed as described above for CBI receptor localisation in perivascular sensory nerves.

Specificity of the immunostaining was evaluated by omission of the primary antibody and processed. Under these conditions, no staining was observed in the vessel wall of either control or cirrhotic rats.

\section{Statistical analysis}

Relaxation was expressed as a percentage of the contraction induced by phenylephrine. $\mathrm{EC}_{50}$ was defined as the concentration of agonist effective in producing a response which was $50 \%$ of the maximum response $\left(\mathrm{V}_{\max }\right)$, and $\mathrm{pEC}_{50}$ corresponds to the negative decimal logarithm of $\mathrm{EC}_{50}$.

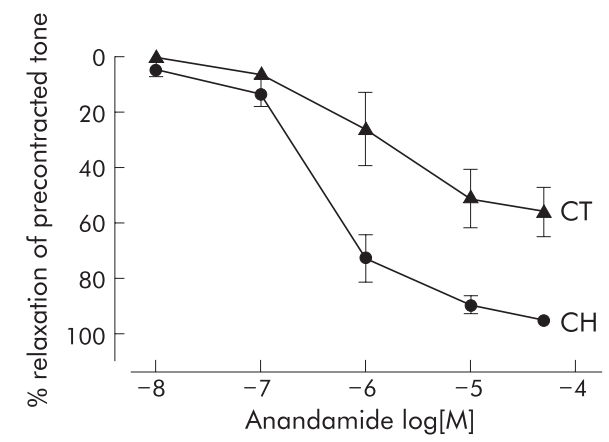

Figure 1 Anandamide induced relaxation in mesenteric arteries from cirrhotic and control rats: role of cannabinoid $C B 1$ receptor. Log concentration-response curves for relaxation to anandamide of phenylephrine $(10 \mu \mathrm{M})$ precontracted intact mesenteric arteries of cirrhotic $(\mathrm{CH}, \mathrm{n}=7)$ and control $(\mathrm{CT}, \mathrm{n}=6)$ rats; $\mathrm{n}$ indicates the number of rats used in each condition. $\mathrm{p}<0.001, \mathrm{CH}$ versus $\mathrm{CT}$ (two way ANOVA). 


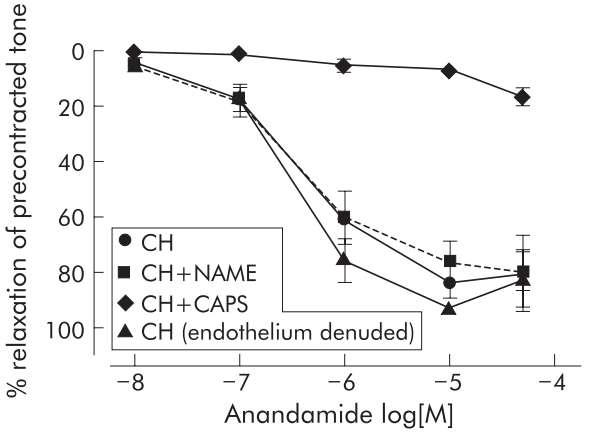

Figure 2 Anandamide induced relaxation in mesenteric arteries from cirrhotic rats: role of endothelium and nitric oxide. Log concentrationresponse curves for relaxation to anandamide in phenylephrine $(10 \mu \mathrm{M})$ precontracted intact mesenteric arteries (cirrhotic rats $(C H), n=7$ ), mesenteric arteries incubated with L-NAME $(100 \mu M, n=10)$, endothelium denuded mesenteric arteries $(n=5)$, and mesenteric arteries incubated with capsaicin (CAPS $10 \mu \mathrm{M}, \mathrm{n}=8$ ) of cirrhotic rats. $\mathrm{n}$ indicates the number of rats used in each condition. $\mathrm{p}<0.001$, $\mathrm{CH}+\mathrm{CAPS}$ versus all other conditions (two way ANOVA).

Estimated $\mathrm{pA}_{2}$ was obtained from the equation, $\mathrm{pA}_{2}=\log$ $\left(\left(\mathrm{EC}_{50 \mathrm{~A}} / \mathrm{EC}_{50 \mathrm{C}}\right)-1\right)-\log \left[\right.$ antagonist], where $\mathrm{EC}_{50 \mathrm{~A}}$ is the agonist $\mathrm{EC}_{50}$ in the presence of antagonist and $\mathrm{EC}_{50 \mathrm{C}}$ is the control agonist of $\mathrm{EC}_{50}$. Statistical comparisons of concentration-response curves were made by two way ANOVA of the whole data set, followed by Bonferroni's test for determining significant differences between treatment groups. Differences between $\mathrm{pEC}_{50}$ values or maximum relaxation were assessed by the unpaired Student's $t$ test. Data are expressed as mean (SEM) and were considered significant at a p level of 0.05 or less. The study was performed according to the criteria of the Investigation and Ethics Committee of the Hospital Clínic Universitari.

\section{RESULTS}

Histological examination of livers from all animals treated with $\mathrm{CCl}_{4}$ showed a finally granulated surface and the characteristic features of cirrhosis.

AEA induced a concentration dependent relaxation of endothelium intact, phenylephrine precontracted isolated mesenteric arteries from both cirrhotic and control rats at

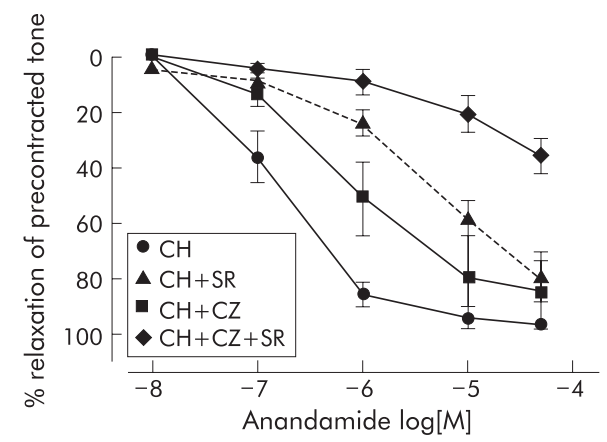

Figure 3 Anandamide induced relaxation in mesenteric arteries from cirrhotic rats: role of cannabinoid $\mathrm{CB} 1$ and transient receptor potential vanilloid type 1 protein (TRPV1) receptors. Log concentration-response curves for relaxation to AEA in phenylephrine $(10 \mu \mathrm{M})$ precontracted intact mesenteric arteries (cirrhotic rats $(\mathrm{CH}), \mathrm{n}=6$ ), mesenteric arteries incubated with SR141716A (SR $3 \mu M, n=6$ ), mesenteric arteries incubated with capsazepine (CZ $5 \mu \mathrm{M}, \mathrm{n}=4)$, and mesenteric arteries incubated with SR141716A plus capsazepine $(C Z+S R, n=5)$ of cirrhotic rats. $n$ indicates the number of rats used in each condition. $p<0.01, \mathrm{CH}$ versus $\mathrm{CH}+\mathrm{SR}$ and $\mathrm{CH}$ versus $\mathrm{CH}+\mathrm{CZ}+\mathrm{SR} ; \mathrm{p}<0.05, \mathrm{CH}$ versus $\mathrm{CH}+\mathrm{CZ}$ (two way ANOVA). doses ranging from $10^{-8} \mathrm{M}$ to $5 \times 10^{-5} \mathrm{M}$ (fig 1). The concentration response to AEA was shifted to the left $(\mathrm{p}<0.001)$. The maximal response to AEA $\left(\mathrm{V}_{\max }\right)$ was approximately twofold higher in cirrhotic than in control arteries $\quad(93.14 \quad(1.5) \% \quad(\mathrm{n}=7) \quad v \quad 56.41 \quad(9.5) \% \quad(\mathrm{n}=6)$, respectively; $\mathrm{p}<0,01)$.

Additional experiments were conducted in intact, in endothelium denuded, and in intact L-NAME pretreated mesenteric arteries of cirrhotic rats. As shown in fig 2, no differences were observed in the response to AEA among the three experimental conditions. Increasing doses of the endocannabinoid resulted in similar values for both $\mathrm{V}_{\max }$ (93.5 (1.6)\% in intact vessels; 91.9 (1)\% in endothelium denuded arteries; and $92.5(6.9) \%$ in L-NAME pretreated vessels) and $\mathrm{pEC}_{50}(6.4$ (0.13); 6.45 (0.14); and 5.83 (0.33), respectively), indicating that the relaxation induced by AEA in cirrhotic vessels is not dependent on the functional integrity of the endothelium dependent NO metabolic pathway.

Figure 2 also shows the results obtained at preincubaiting isolated cirrhotic arteries with capsaicin, a selective neurotoxin for $\mathrm{C}$ fibres that results in functional desensitisation of the receptor system in perivascular nerves. Capsaicin pretreatment completely prevented the vasodilation induced by AEA in cirrhotic vessels, providing functional evidence that receptors located in the perivascular nerves are involved in the vascular effect of this cannabinoid.

\section{Effect of CB 1 and TRPV 1 receptor blockade in mesenteric arteries of cirrhotic rats}

To ascertain the contributory role of cannabinoid and vanilloid receptors in the vasorelaxant effect of AEA in mesenteric arteries of cirrhotic rats, vascular reactivity assays were also conducted under conditions of CBI and TRPVI receptor blockade (fig 3). AEA produced a concentration dependent relaxation of phenylephrine precontracted mesenteric arteries $\left(\mathrm{pEC}_{50}=6.9(0.23) ; \mathrm{V}_{\max }=96.8(0.8) \% ; \mathrm{n}=6\right)$. The CBI receptor antagonist SRI41716A $(3 \mu \mathrm{M})$ shifted the concentration response curve to AEA to the right $(p<0.01)$, with no significant reduction in maximal relaxation $\left(\mathrm{pEC}_{50}=5.30\right.$ (0.28); $\left.\mathrm{V}_{\max }=80.6(7) \% ; \mathrm{n}=6\right)$. Moreover, incubation with the TRPVI antagonist capsazepine also shifted the concentration response curve to AEA $\left(\mathrm{pEC}_{50}=6.15(0.23), \mathrm{n}=4\right)$ to the right $(\mathrm{p}<0.05)$ with no modification in maximum relaxation (84.9 (14)\%). Estimation of the magnitude of the shifts from the $\mathrm{EC}_{50}$ values gave a 44.7 -fold shift for SR141716A and a 6.45-fold shift for capsazepine, which correspond to estimated pA2 values of 7.17 for SR 141716A and 6.04 for capsazepine. When both antagonists were incubated together, there was stronger inhibition of the response to AEA at the concentrations used. Nevertheless, the limited solubility of AEA

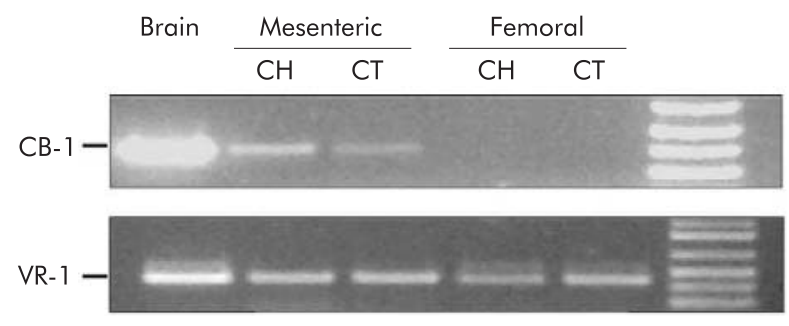

Figure $4 m R N A$ expression of cannabinoid $C B 1$ and transient receptor potential vanilloid type 1 protein (TRPV1) receptors in mesenteric and femoral arteries of control (CT) and cirrhotic (CH) rats. Representative reverse transcription-polymerase chain reaction of mRNA for $C B 1$ and TRPV1 (VR-1) receptor in second and third order mesenteric arteries and distal femoral arteries of control and cirrhotic rats is shown. 


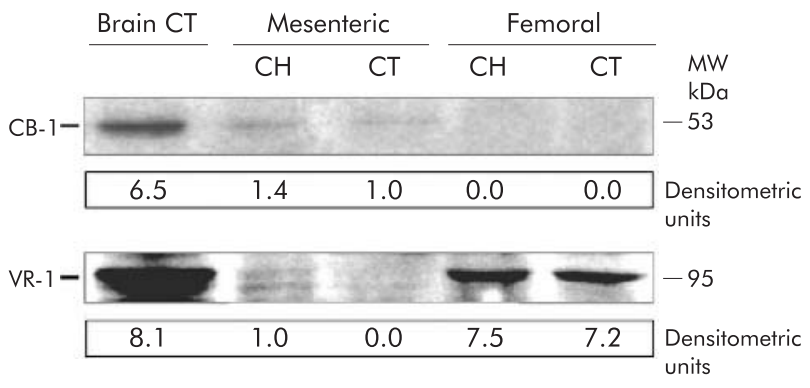

Figure 5 Western blot analysis of cannabinoid $C B 1$ and transient receptor potential vanilloid type 1 (TRPV1) protein in mesenteric and femoral arteries of control (CT) and cirrhotic $(\mathrm{CH})$ rats. A representative western blot of the $C B 1$ receptor and the TRPV1 receptor in mesenteric and femoral arteries of control and cirrhotic rats with ascites is shown. Densitometric analysis of the representative western blots is shown at the bottom of the panels.

precluded the use of higher concentrations and the construction of a full concentration response curve.

As shown in fig 3, vessel pretreatment with the TRPVl receptor antagonist capsazepine also significantly attenuated the relaxation induced by the endocannabinoid although to a lesser extent than that observed under conditions of $\mathrm{CBl}$ receptor blockade. Finally, simultaneous CBI and TRPVI receptor blockade almost completely prevented the AEA induced relaxation in isolated mesenteric arteries of cirrhotic rats.

In addition, AEA had no vasodilatatory effect on distal femoral arteries of cirrhotic and control rats, indicating the existence of a selective action of the cannabinoid on splanchnic circulation. Similar results were observed in isolated vessels of control rats (data not shown).

\section{CB 1 and TRPV 1 mRNA expression}

As shown in fig 4, second and third order mesenteric arteries, from both control and cirrhotic rats, expressed a band of $425 \mathrm{bp}$, corresponding to the CB1 receptor mRNA. This band was absent in samples from distal femoral arteries, which is in agreement with the lack of response to AEA observed in this type of vessel. In contrast, both mesenteric and femoral arteries expressed mRNA for TRPVI, as reflected by amplification of a band of $442 \mathrm{bp}$ in all samples.

\section{CB 1 and TRPV 1 protein expression}

Mesenteric arteries of cirrhotic and control rats showed a specific band of approximately $53 \mathrm{kDa}$ that was identified as CBl protein due to its correspondence with the band obtained in the positive control, thus providing evidence of antibody specificity (fig 5). Paralleling the results obtained on analysing CBI PCR products, enhanced abundance of CBI protein was detected in cirrhotic mesenteric arteries compared with controls, and no protein expression of this receptor was observed in the femoral arteries of both groups of animals. Western blot analysis of TRPVI receptor yielded a specific band at the expected molecular weight of approximately $95 \mathrm{kDa}$ in the positive control. In contrast with strong TRPVl expression found in femoral arteries of cirrhotic and control rats, a faint signal was detected in cirrhotic mesenteric vessels and no detectable TRPVl protein was observed in mesenteric vessels isolated from control rats (fig 5).

\section{Immunodetection of CB 1 receptors in mesenteric vessels}

Confocal microscopy analyses were performed to unveil CBI receptors in the different layers of mesenteric vessels. Figure 6
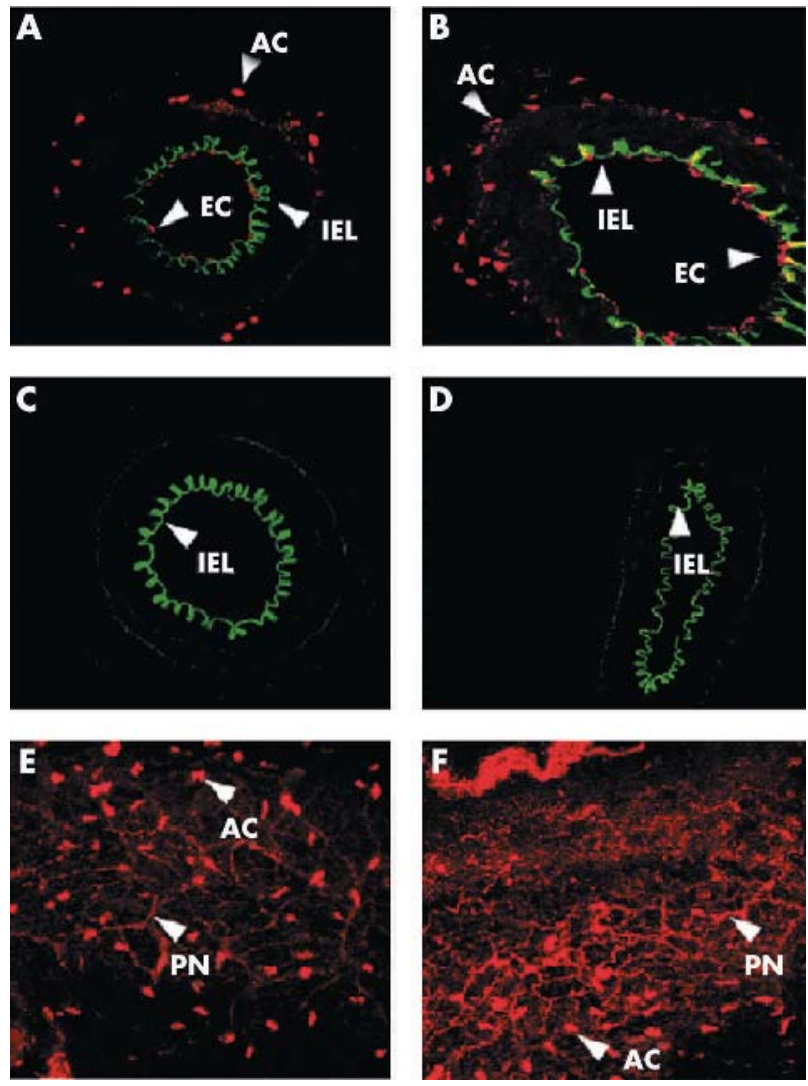

Figure 6 Immunodetection of cannabinoid $\mathrm{CB} 1$ receptors in mesenteric vessels. Representative confocal imaging of $C B 1$ receptor in sections of mesenteric resistance arteries of control $(A)$ and cirrhotic rats with ascites (B). (C, D) Negative controls of the fluorescence produced by omission of the primary antibody in arteries from the same animals. Fluorescence in whole mounted vessels of control (E) and cirrhotic (F) rats is also shown. Natural autofluorescence of the elastic components of the arterial wall are also depicted $(n=5)$. Image dimensions $256 \times 256 \mu \mathrm{m}$. AC,

adventitial cells; EC, endothelial cells; IEL, internal elastic lamina; PN, perivascular nerves.

shows that $\mathrm{CBl}$ receptor (red) was mostly present in adventitial cells and only slightly in endothelial cells, in both control and cirrhotic mesenteric vessels. As shown, CBl receptor density in adventitial cells from cirrhotic vessels (fig 6B) was higher than that in control vessels (fig 6A). These findings were in accordance with the response to AEA observed in these vessels. No expression of CBI receptor was detected in the smooth muscle cell layer. Negative (fig 6C, D) control slides of control and cirrhotic mesenteric resistance vessels showed no staining.

To determine whether the $\mathrm{CBl}$ receptor is expressed in perivascular sensory nerves innervating mesenteric resistance arteries, fluorescent immunohistochemistry in whole mounted vessels combined with confocal microscopy was also performed. Confocal microscopy showed that perivascular sensory nerves innervating mesenteric resistance arteries from control and cirrhotic rats were positively stained for $\mathrm{CBl}$ (fig 6E, 6F). No staining was observed in arteries from the same animals in the absence of primary antibody (data not shown).

\section{DISCUSSION}

The main aim of the present study was to determine whether enhanced vascular reactivity to AEA selectively occurred in the mesenteric resistance vessels of cirrhotic rats. The results indicate that AEA is an important specific splanchnic 
vasodilator acting predominantly in a non-endothelium, nonNO dependent manner via interaction with two different types of receptors, CBI and TRPVI receptors, which are mainly located in perivascular sensory nerve terminals of the mesenteric resistance arteries of cirrhotic rats.

In terms of vasorelaxation to AEA, we have shown that isolated mesenteric resistance arteries of cirrhotic rats with ascites relaxed to a greater extent than vessels of control rats. Because previous investigations have also found increased circulating levels of AEA in cirrhosis, ${ }^{56}$ our results indicate that the endocannabinoid system may have greater local vasodilator activity in the splanchnic circulation under this condition. In agreement with previous investigations in mesenteric arterial preparations, ${ }^{9}$ our results showed that L-NAME had no effect on the pronounced relaxation induced by AEA in the mesenteric vessels of cirrhotic animals, suggesting that endothelium derived NO does not play a major role in this response. Consistent with the lack of effect of L-NAME, endothelial denudation also did not alter the vasorelaxation induced by the endocannabinoid in cirrhotic vessels, indicating that the effect of AEA on mesenteric vessels is not dependent on functional endothelium integrity. This is in keeping with several previous studies suggesting that the relaxation induced by AEA is largely independent of endothelium components. ${ }^{9-11} \mathrm{CBl}$ receptors have been described in the perivascular sensory nerves of mesenteric arteries. ${ }^{12}$ Moreover, several studies have also indicated that AEA may exert its vasorelaxant activity by stimulating CGRP release from sensory nerves through activation of TRPVI receptors. ${ }^{13}$ In this regard, recent studies have shown that neonatal capsaicin treatment blocks the development of the hyperdynamic circulation and ascites formation in bile duct ligated cirrhotic rats. ${ }^{14}$ Therefore, to elucidate whether a perivascular rather than an endothelial component could be involved in the increased AEA induced vasorelaxation of the cirrhotic mesenteric arteries, experiments were also performed in the presence of capsaicin. This substance activates primary sensory nerves that then become refractory to subsequent stimuli because of desensitisation and/or neurotransmitter depletion. ${ }^{15}$ Pretreatment with capsaicin fully abolished the AEA induced relaxation in resistance mesenteric arteries of cirrhotic rats, providing functional evidence that the signalling pathway ultimately resulting in vasorelaxation of cirrhotic mesenteric arteries is mainly located in the adventitia, rather than in the endothelial layer of the vessel.

The involvement of cannabinoid and/or vanilloid receptors in the vasorelaxation to AEA in mesenteric cirrhotic vessels was examined using both SR141716A and capsazepine. The CBl receptor antagonist produced a marked rightward shift in the response curve to AEA without affecting the maximal response produced by the endocannabinoid. These results, which are coincident with previous investigations by Randall and colleagues, ${ }^{16}$ favour the involvement of $\mathrm{CBl}$ receptors. The fact that capsaicin inhibited responses to AEA together with the shift to the right of the concentration response curve to AEA by capsazepine could be explained by its ability to stimulate CGRP release from capsaicin sensitive sensory nerves as a consequence of activation of vanilloid TRPVI receptors. ${ }^{13}$ Interestingly, simultaneous blockade of $\mathrm{CBI}$ and TRPVI receptors almost fully prevented the vasorelaxant effect of AEA in cirrhotic vessels which is a strong additional indication that both $\mathrm{CBI}$ and TRPVI receptors are involved in the vasorelaxant effect of AEA in the mesenteric resistance vessels of cirrhotic rats.

Previous investigations have indicated that vasorelaxation induced by AEA is not a general phenomenon occurring in all vascular areas. This endocannabinoid has been shown to cause cerebrovascular, mesenteric, and coronary dilatation in the rat, ${ }^{16-18}$ but not in the aorta or carotid artery. ${ }^{19} 20$ This was also confirmed in the present investigation as no vascular response to AEA was observed in femoral resistance arteries of cirrhotic and control rats. Our results emphasise the tissue selectivity of endocannabinoids and point to AEA as an important local regulator of vascular tonicity in the mesenteric circulation in pathological conditions such as hepatic cirrhosis.

To further confirm the presence of $\mathrm{CBl}$ receptor mRNA and protein in resistance mesenteric arteries, RT-PCR and western blot experiments were performed. To our knowledge, this is the first study demonstrating CBI mRNA expression in third order mesenteric arteries of adult rats, with CBI transcript expression being higher in cirrhotic than in control animals. Furthermore, no mRNA expression was detected in femoral arteries, irrespective of whether they were obtained from cirrhotic or control rats. Western blot experiments yielded parallel results to those found in the RT-PCR analyses. In both brain and mesenteric arteries, the CBI specific antibody recognised the $\mathrm{CBl}$ protein, while in femoral arteries $\mathrm{CBI}$ protein expression was absent. Moreover, receptor signal intensity was higher in protein extracts obtained from mesenteric vessels of cirrhotic animals than in those of control animals. These findings coincide with those obtained in the vascular reactivity assays and suggest a major involvement of the $\mathrm{CBl}$ receptor in the increased vascular responsiveness to AEA detected in the mesenteric arteries of cirrhotic rats.

The results of TRPVl expression analysis were less conclusive than those for the $\mathrm{CBI}$ receptor. A PCR product of the expected size was amplified for rat brain and mesenteric and femoral arteries, with no distinctive pattern expression between cirrhotic and control samples. As the amplified products encode for the functional receptor protein, we thereafter verified transcription of this mRNA into protein by western blot. An immunoreactive protein at approximately $96 \mathrm{kDa}$ was identified in protein extracts from brain and femoral and mesenteric arteries although expression in the latter was very weak in comparison with the other tissues. This clearly differs from the vascular reactivity experiments in femoral arteries. The lack of response to AEA in femoral arteries despite the existence of TRPVI receptors could be the consequence of the experimental conditions used in the current experiments but also could be due to the particular characteristics of this receptor. TRPVI is a non-selective cation channel that integrates noxious stimuli and can also be activated by AEA. ${ }^{1521}$ However, significant differences have been described in the efficacy of AEA between different tissues. ${ }^{22}$ Differences in efficacy of AEA at the TRPVI in different tissues may result from several factors, the most important being AEA membrane transporter and fatty acid amide hydrolase activities. ${ }^{15} 23$ In mesenteric arteries however, our functional studies together with the vascular expression assays indicate the existence of a TRPVI component. Therefore, it is likely that, in addition to activating the $\mathrm{CB} 1$ receptor in resistance mesenteric arteries, AEA may also serve as an endogenous mesenteric TRPVl stimulator further contributing to the splanchnic vasorelaxation occurring in advanced liver disease.

TRPVl receptors are almost exclusively expressed in primary sensory neurones that surround and innervate resistance mesenteric arteries. ${ }^{24}$ However, the CBl receptor is more widely expressed among the different artery cell types, including endothelial and vascular smooth muscle cells ${ }^{2}{ }^{4}$ and also in perivascular nerves. ${ }^{4}$ Therefore, we studied CBl cellular distribution within cirrhotic and control mesenteric arteries using immunohistochemistry. Specific $\mathrm{CBl}$ staining was detectable in endothelial and adventitial cells. We also found that $\mathrm{CB} 1$ receptor immunoreactivity was 
more intense in adventitial cells of cirrhotic vessels than in those of controls. This pattern of staining is consistent with the increased $\mathrm{CBl}$ mRNA and protein expression observed in cirrhotic arteries and supports the results of the vascular reactivity assays showing an endothelium independent increased vasorelaxant response to AEA in mesenteric arterial vessels of cirrhotic rats.

\section{ACKNOWLEDGEMENTS}

This work was supported by grants from Fondo de Investigación Sanitaria (FIS 02/0588, FIS 01/1514, and FIS 01/1513 to J Ros, W Jiménez, and JM Campistol, respectively), Marató (U2000-TV3-510) to JM.Campistol, and Instituto de Salud Carlos III (CO2/03). M Domenicali was a visiting scientist from the Department of Internal Medicine, Cardioangiology and Hepatology, Università di Bologna, Italy. P Cejudo-Martín had a grant from FIS (01/1514) and M Crespo had a grant from FIS 01/1513. M Morales-Ruiz is an investigator of the Programa Ramón y Cajal (Ministerio de Ciencia y Tecnología).

\section{Authors' affiliations \\ M Domenicali, J Ros, G Fernández-Varo, P Cejudo-Martín, M Morales- Ruiz, W Jiménez, Hormonal Laboratory, Hospital Clínic Universitari, Institut d'Investigacions Biomèdiques August Pi i Sunyer (IDIBAPS) and Universidad de Barcelona, Barcelona. Spain \\ M Crespo, J-M Campistol, Renal Trasplant Unit, Hospital Clínic Universitari, Institut d'Investigacions Biomèdiques August Pi i Sunyer (IDIBAPS), Universidad de Barcelona and Instituto Reina Sofía de Investigaciones Nefrológicas (IRSIN), Barcelona, Spain \\ A M Briones, E Vila, Therapeutic, Toxicology and Pharmacology Department, Universitat Autònoma de Barcelona, Barcelona, Spain \\ V Arroyo, J Rodés, Liver Unit, Hospital Clínic Universitari, Institut $d^{\prime}$ Investigacions Biomèdiques August Pi i Sunyer (IDIBAPS), Universidad de Barcelona and Instituto Reina Sofía de Investigaciones Nefrológicas (IRSIN), Barcelona, Spain \\ Conflict of interest: None declared \\ REFERENCES \\ 1 Walker JM, Krey, Chu CJ, et al. Endocannabinoids and related fatty acid derivatives in pain modulation. Chem Phys Lipids 2002;121:159-72. \\ 2 Högestätt ED, Zygmunt PM. Cardiovascular pharmacology of anandamide. Prostaglandins Leukot Essent Fatty Acids 2002;66:343-51 \\ 3 García N Jr, Jarai Z, Mirshahi F, et al. Systemic and portal hemodynamic effect of anandamide. Am J Physiol 2001;280:G14-20. \\ 4 Ralevic V, Kendall DA, Randall MD, et al. Cannabinoid modulation of sensory neurotrasmission via cannabinoid an vanilloid receptor: roles in regulation of cardiovascular system. Life Sci 2002;71:2577-94.}

5 Ros J, Clària J, To-Figueras J, et al. Endogenous cannabinoids: a new system involved in the homeostasis of arterial pressure in experimental cirrhosis in the rat. Gastroenterology 2002;122:85-93.

6 Batkai S, Jarai Z, Wagner JA, et al. Endocannabinoids acting at vascular CB1 receptor mediate the vasodilatated state in advanced liver cirrhosis. Nat Med 2001;7:827-32.

7 Clària J, Jimenez W. Renal dysfunction and ascites in carbon tetrachlorideinduced cirrhosis in rats. In: Arroyo V, Ginès P, Rodés J, et al. Ascites and renal dysfunction in the liver disease. Pathogenesis, diagnosis and treatment. Malden MA: Blackwell Science, 1999:379-96.

8 Wigg ST, Tare M, Tonta MA, et al. Comparison of effect of diabetes mellitus on an EDHF-dependent and EDHF-independent artery. Am J Physiol Heart Circ Physiol 2001;281:H232-40.

9 Harris D, McCulloch Al, Kendall DA, et al. Characterization of vasorelaxant responses to anandamide in the rat mesenteric arterial bed. J Physiol 2002;539:893-902.

10 White R, Hiley CR. A comparison of EDHF-mediated and anandamideinduced relaxation in the rat mesenteric artery. Br J Phamacol 1997; 122:1573-84.

11 Di Marzo V, De Petrocellis L, Fezza F, et al. Anandamide receptors. Prostaglandins Leukot Essent Fatty Acids, 2002;66:377-91.

12 Ralevic V. Cannabinoid modulation of peripheral autonomic and sensory neurotransmission. Eur J Pharmacol 2003;472:1-21.

13 Zygmunt PM, Petersson J, Andersson BA, et al. Vanilloid receptors on sensory nerves mediate the vasodilator action of anandamide. Nature 1999;400:452-7.

14 Li Y, Song D, Lee SS. Effect of neonatal capsaicin treatment on haemodynamics and renal function in cirrhotic rats. Gut 2003;52:293-9.

15 Szallasi A, Blumberg PM. Vanilloid (capsaicin) receptors and mechanisms. Pharmacol Rev 1999;51:159-212.

16 Randall MD, Alexander SPH, Bennett T, et al. An endogenous cannabinoid as an endothelium-derived vasorelaxant. Biochem Biophys Res Commun 1996;229:114-20.

17 Ellis EF, Moore SF, Willoughby KA. Anandamide and $\Delta^{9}-\mathrm{THC}$ dilation of cerebral arterioles is blocked by indomethacin. Am J Physiol 1995;38:H1859-64.

18 Randall MD, McCulloch Al, Kendall DA. Comparative pharmacology of endothelium-derived hyperpolarizing factor and anandamide in rat isolated mesentery. Eur J Pharmacol 1997;333:191-7.

19 Holland $M$, Challis RA, Standen NB, et al. Cannabinoid CB1 receptors fail to cause relaxation, but couple via $G_{l} / G_{O}$ to inhibition of adenylyl cyclase in carotid artery smooth muscle. Br J Pharmacol 1999; 128:597-604.

20 Darker IT, Millns PJ, Selbie L, et al. Cannabinoid (CB1) receptor expression is associated with mesenteric resistance vessels but not thoracic aorta in the rat. Br J Pharmacol 1998;125:95P

21 Ross RA. Anandamide and vanilloid TRPVI receptors. Br J Pharmacol 2003;140:790-801.

22 Andersson DA, Adner M, Hogestatt ED, et al. Mechanisms underlying tissue selectivity of anandamide and other vanilloid receptor agonists. Mol Pharmacol 2002;62:705-13.

23 De Petrocellis L, Cascio MG, Di Marzo V. The endocannabinoid system: a general view and latest additions. Br J Pharmacol 2004;141:765-74.

24 Caterina MJ, Julius D. The vanilloid receptor: a molecular gate-way to the pain pathway. Annu Rev Neurosci 2001;24:487-517. 